\title{
Theoretical study of two states reactivity of NO activation on iron atom
}

\author{
Xiaoman Wang, Yaxin Su, Wenyu Liao and Wenyi Deng \\ School of Environmental Science and Engineering, Donghua University, Shanghai 201620, P.R. China
}

\begin{abstract}
The mechanism of Fe+NO was calculated by the Density Functional Theory (DFT) with the B3LYP methods combined with the $6-311+\mathrm{G}(\mathrm{d}, \mathrm{p})$ basis set. The geometry of reactants, transition states, intermediates and products of two reaction systems were completely optimized, and all the transition states were verified by the vibration analysis and intrinsic reaction coordinate (IRC) calculations. The "Two State Reactivity (TSR)" was used to analyze the reaction mechanisms; Results showed that the reaction system preferentially involves low-spin state entrance channel and the high-spin state exit channel. In the reaction channel, the crossing point appears, which would effectively reduce the activation energy and increase the release of reaction heat, play a significant and beneficial role in the kinetic and thermodynamic aspects of this catalytic reaction.
\end{abstract}

\section{Introduction}

The nitrogen oxides $\left(\mathrm{NO}_{\mathrm{x}}\right)$ emission from fossil fuel combustion is a major environmental problem we are currently facing and the elimination of $\mathrm{NO}_{\mathrm{x}}$ from flue gases emitted from coal-fired boilers and vehicles is an important issue in atmospheric pollution control. The catalytic reduction of $\mathrm{NO}_{\mathrm{x}}$ is a very effective technology for the removal of $\mathrm{NO}_{\mathrm{x}}$. Over the last two decades, transition metal clusters have attracted much interest in the application of heterogeneous catalysis due to their unusual physical and chemical behaviour [1-5]. Among the transition metals, iron is a desirable catalyst owing to the abundant reserves, environmental friendly character and active properties, which was investigated by researchers widely. Recent experiments showed that metallic iron can directly reduce $\mathrm{NO}$ into $\mathrm{N}_{2}$ according to the following reaction $[6,7]$.

$$
\mathrm{Fe}+\mathrm{NO} \rightarrow \mathrm{N}_{2}+\mathrm{Fe}_{\mathrm{x}} \mathrm{O}_{\mathrm{y}}
$$

Unfortunately, there is not a solid conclusion on the final chemical forms of iron oxides so far. By XRD (Xray Diffraction)analysis, $\mathrm{Su}$ et al. [8] found that the iron surface was oxidized after reducing $\mathrm{NO}$ and both $\mathrm{FeO}$, $\mathrm{Fe}_{3} \mathrm{O}_{4}$ and $\mathrm{Fe}_{2} \mathrm{O}_{3}$ were formed depending on the temperature. However, the XRD analysis could only check the final reaction products during NO reduction by iron. The reaction pathway and evolution process, binding, energies, etc., was not fully understood yet.

It has been known that Density Functional Theory (DFT) can offer significant insight to understand the nitric oxide activation or reduction by small iron clusters. For example, Blagojevic and co-workers [9] investigated the catalytic decomposition of nitric oxide by the $\mathrm{Fe}^{+}$.The results show that $\mathrm{Fe}^{+}$can lower the activation energy effectively. Heyden et al. [10] researched nitrous oxide decomposition over Fe-ZSM-5 in the presence of nitric oxide by means of DFT. They reported that single iron sites $\left(\mathrm{Z}^{-}[\mathrm{FeO}]^{+}\right)$are converted into a novel active Iron center $\left(\mathrm{Z}^{-}[\mathrm{FeOH}]^{+}\right)$in the presence of $\mathrm{NO}$, these sites are capable of promoting the dissociation of $\mathrm{N}_{2} \mathrm{O}$ into a surface oxygen atom and gas-phase $\mathrm{N}_{2}$.

Studies have manifested that the catalytic properties of iron clusters vary with the size of metal clusters [11]. Sun et al. [12] calculated the reaction of methane activated by iron atom/dimer, and their calculation results indicated that the iron dimer $\mathrm{Fe}_{2}$ had a stronger catalytic effect on the activation of methane than the iron atom. However, the catalytic effect of NO activation on varied size of small iron cluster is undefined. Gutsev et al. [13] et al. investigated the electronic and geometrical structures of $\mathrm{Fe}_{\mathrm{n}} \quad(\mathrm{n}=1 \sim 6)$ with associative and dissociative attachments of $\mathrm{NO}$, as well as the corresponding negatively and positively charged ions, as well as the corresponding negative and positive charge ions ,but the results are lack of the path of the reaction kinetics.

On the surface of iron, NO may be reduced by many iron atoms. However, as a preliminary understanding of the reaction of $\mathrm{NO}$ with $\mathrm{Fe}$, it is necessary to know how a single NO molecular reacts with one iron atom. On this basis, the further calculation of NO molecular with iron clusters will be studied. Therefore, in present work, the reaction pathway and evolution process of $\mathrm{NO}$ with one iron atom will be calculated based on DFT method.

\section{Computational methodology}

All calculations herein were carried out by the Gaussian 09 [14] program computational package with ab initio and density functional methods. As to the DFT, Becke's 
$[15,16]$ three-parameter hybrid exchange functional combined with the Lee-Yang-Parr [17] non-local correlation functional, namely B3LYP, was selected to perform geometry optimizations and frequency calculations in the systems. At the same time, $6-311+\mathrm{G}(\mathrm{d}$, p) basis set was employed for the structural optimization of all reactants, intermediates, transition states, and products involved in the reactions of $\mathrm{Fe}$ with $\mathrm{NO}$. Owing to the accuracy of calculation and reasonability of timeassuming, B3LYP has been applied in the calculations of transition metals extensively [18-20]. Kwon et al. [21] investigated the vibrational frequencies and adsorption energies of iron hydroxides on phosphates, the results show that the frequencies calculated by DFT is consistent with the frequencies of experimental IR data [22, 23].

In this paper, the B3LYP/6-311+G(d, p) basis set was utilized to calculate all geometry and energy of the stationary points of the potential energy surfaces (PES) in $\mathrm{Fe}+\mathrm{NO}$ system. Meanwhile, the energy of all geometries were revised by the zero point energy (ZPE). Furthermore, in order to confirm the crucial structures of transition and intermediates, the intrinsic reaction coordinate (IRC) calculations was applied to perform the minimum reaction way.

\section{Results and discussions}

\subsection{Fe-NO system}

In the $\mathrm{Fe}+\mathrm{NO}$ system, according to the previous works [11], the ground state of the iron atom is a quintet state $\left({ }^{5} \mathrm{D}\right)$ (the total multiplicity of $\mathrm{Fe}-\mathrm{NO}: \mathrm{M}=6$ ), the occupation of iron atom corresponding to quintet state is $3 d^{6} 4 s^{2}$, which is consistent with the Mebel and Hwang's work [24]. Notably, there is another occupation of the iron atom $\left(3 \mathrm{~d}^{7} 4 \mathrm{~s}^{1}\right)$, which corresponds to the triplet state $\left({ }^{3} \mathrm{~F}\right)$ (the total multiplicity of Fe-NO: $\mathrm{M}=4$ ). Tatewaki and co-workers [25] have manifested that the ${ }^{5} \mathrm{D}-{ }^{3} \mathrm{~F}$ splitting energy is $1.32 \mathrm{eV}$, which is in line with the experimental data [26] $(34.1 \mathrm{kCal} / \mathrm{mol})$.

Based on that, in the $\mathrm{Fe}+\mathrm{NO}$ system, we only consider the NO activation on iron atom by quartet and sextet state. Intermediates and transition states on the quartet potential energy surface (PES) are labeled as ${ }^{4} \mathrm{C}$ and ${ }^{4} \mathrm{TS}$. Similarly, those on the sextet state PES are labelled as ${ }^{6} \mathrm{C}$ and ${ }^{6} \mathrm{TS}$. The optimized geometries of various intermediates and transition states for the Fe-NO system by DFT are shown in Fig. 1. While Table 1 gives the information regarding the lowest-frequency vibrational modes. The reaction pathways between the iron atom and NO are plotted in Fig. 1 and Fig. 2. Bond angle are in degrees $\left(^{\circ}\right)$, bond lengths are in angstroms $(\AA)$.

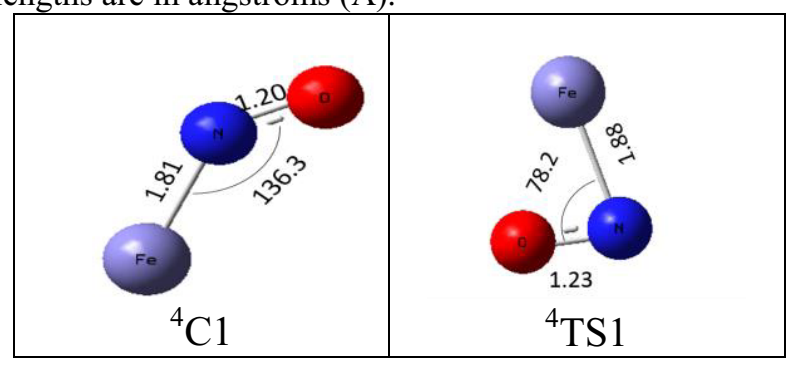

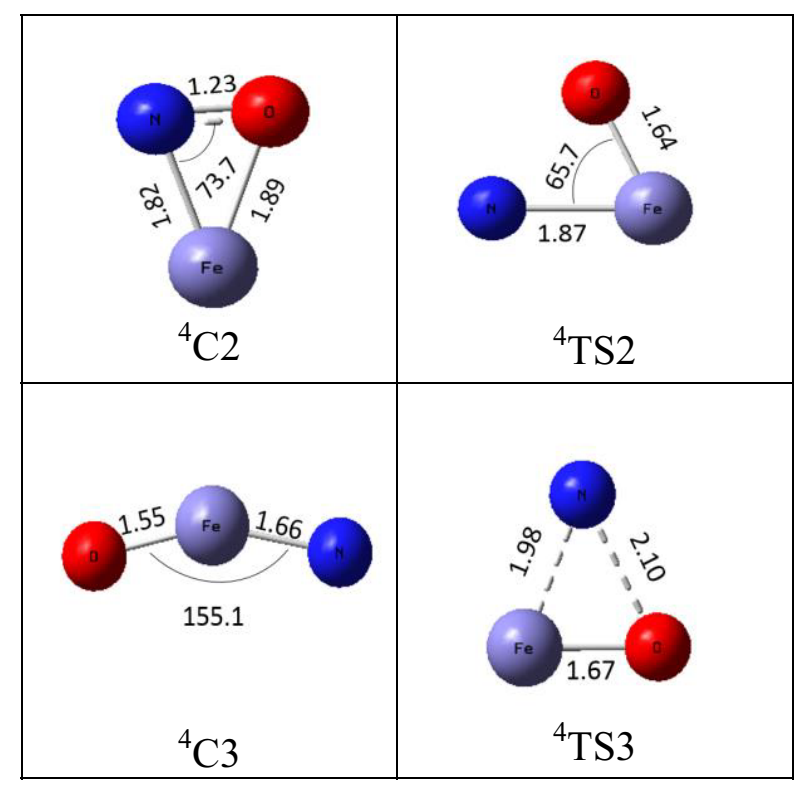
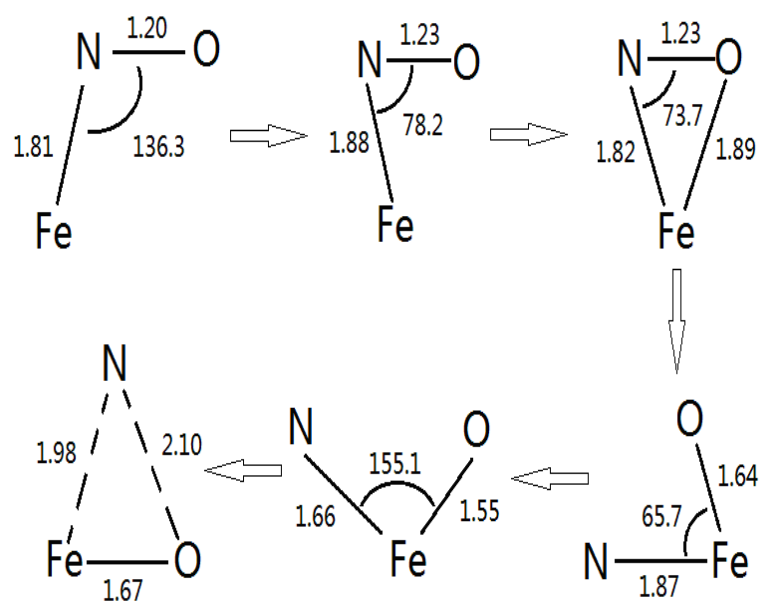

Figure 1. Optimized structures of intermediates and transition states of $\mathrm{NO}$ activation on iron atom on quartet state PES

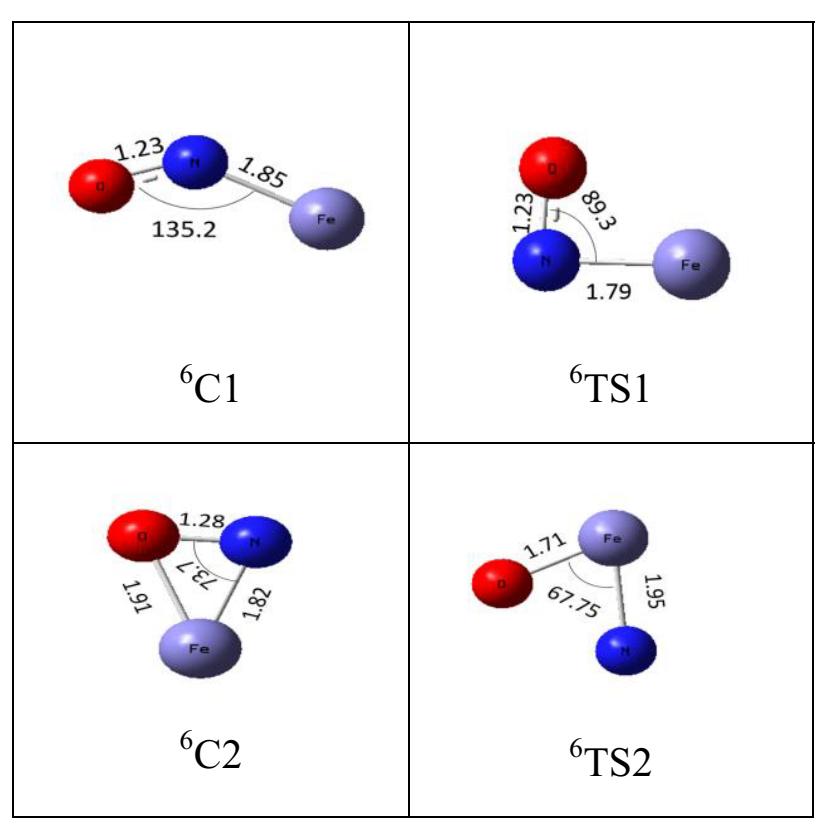



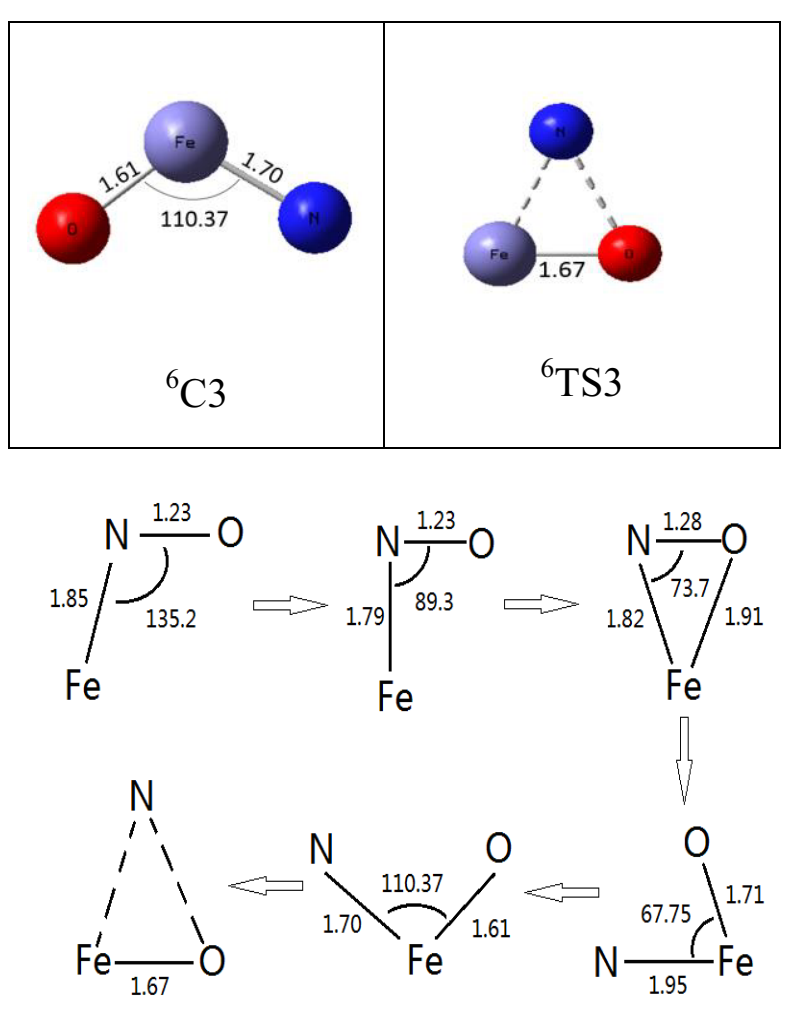

Figure 2. Optimized structures of intermediates and transition states of NO activation on iron atom on sextet state PES

\subsubsection{Reaction process on two states PESs}

With regard to the nitric oxide activated by the metal, previous experimental and DFT studies have demonstrated that in the presence of metals, $\mathrm{N}_{2}$ may be the favorable product [27]. Consequently, attention was paid to the reaction pathways the state PES. Firstly, the frequencies for the saddle points on quartet/sextet states are listed in Table 1. Simultaneously, the diagram of the $\mathrm{Fe}+\mathrm{NO}$ reaction on two states is shown in Fig. 3. The relative energies of various species in the reaction is show in Table 2.

Table 1. Calculated first frequencies $(\mathrm{cm}-1)$ of $\mathrm{Fe}+\mathrm{NO}$ system at B3LYP/6-311+G (d, p) level

\begin{tabular}{cc|cc}
\hline \multicolumn{2}{c|}{ Quartet state } & \multicolumn{2}{c}{ Sextet state } \\
\hline Species & Freq & Species & Freq \\
${ }^{4} \mathrm{C} 1$ & 169.01 & ${ }^{6} \mathrm{C} 1$ & 269.65 \\
${ }^{4} \mathrm{TS} 1$ & $696.77 \mathrm{i}$ & ${ }^{6} \mathrm{TS} 1$ & $269.70 \mathrm{i}$ \\
${ }^{4} \mathrm{C} 2$ & 378.84 & ${ }^{6} \mathrm{C} 2$ & 431.87 \\
${ }^{4} \mathrm{TS} 2$ & $522.86 \mathrm{i}$ & ${ }^{6} \mathrm{TS} 2$ & $431.20 \mathrm{i}$ \\
${ }^{4} \mathrm{C} 3$ & 149.60 & ${ }^{6} \mathrm{C} 3$ & 212.25 \\
${ }^{4} \mathrm{TS} 3$ & $433.56 \mathrm{i}$ & ${ }^{6} \mathrm{TS} 3$ & $474.62 \mathrm{i}$ \\
\hline
\end{tabular}

Before desorption of the $\mathrm{N}$ atom from adducts, the reaction got through the cleavage of $\mathrm{N}-\mathrm{O}$. As we can learn from the Fig. 1 and Fig. 2, our calculations shows that the formation of the Fe-NO adduct was formed on quartet and sextet state channels firstly. We define the energy of the adduct on the sextet state $\left({ }^{6} \mathrm{C} 1\right)$ as benchmark, then the relative energy of ${ }^{4} \mathrm{C} 1$ is -13.15 $\mathrm{kCal} / \mathrm{mol}$, which means the geometry of ${ }^{4} \mathrm{C} 1$ is more stable.
Next step on quartet and sextet PESs, ${ }^{4} \mathrm{C} 2$ and ${ }^{6} \mathrm{C} 2$ are formed via transition states ${ }^{4} \mathrm{TS} 1$ and ${ }^{6} \mathrm{TS} 1$. Correspondingly, the complexes surmount energy barrier of $31.01 \mathrm{kCal} / \mathrm{mol}$ and $38.76 \mathrm{kCal} / \mathrm{mol}$ on two PESs. While imaginary frequencies of the two transition states derive from N-O bond swing, about $696.77 \mathrm{i} \mathrm{cm}^{-1}$ and $269.70 \mathrm{i} \mathrm{cm}^{-1}$, respectively. After the first transition states, the $\mathrm{Fe}-\mathrm{O}$ bonds are formed. The relative energies of ${ }^{4} \mathrm{C} 2$ and ${ }^{6} \mathrm{C} 2$ are $0.67 \mathrm{kCal} / \mathrm{mol}$ and $5.96 \mathrm{kCal} / \mathrm{mol}$.

The cleavage of the N-O bonds occur in the second transition state, which conquer energy barrier of 49.63 $\mathrm{kCal} / \mathrm{mol}$ and $41.45 \mathrm{kCal} / \mathrm{mol}$ on quartet and sextet PESs, respectively. The imaginary frequencies of the second transition state $\left(522.86 \mathrm{i} \mathrm{cm}^{-1}\right.$ for $4 \mathrm{TS} 2,431.20 \mathrm{i} \mathrm{cm}^{-1}$ for ${ }^{6} \mathrm{TS} 2$ ) are assigned to planar rocking modes of $\mathrm{O}-\mathrm{Fe}-\mathrm{N}$. After ${ }^{4} \mathrm{TS} 2$ and ${ }^{6} \mathrm{TS} 2$, angles of $\mathrm{O}-\mathrm{Fe}-\mathrm{N}$ get larger, about $155.1^{\circ}$ and $110.37^{\circ}$. Then, third intermediates $\left({ }^{4} \mathrm{C} 3\right.$ and ${ }^{6} \mathrm{C} 3$ ) are formed, correspondingly, the relative energies of ${ }^{4} \mathrm{C} 3$ and ${ }^{6} \mathrm{C} 3$ are $36.31 \mathrm{kCal} / \mathrm{mol}$ and $27.97 \mathrm{kCal} / \mathrm{mol}$.

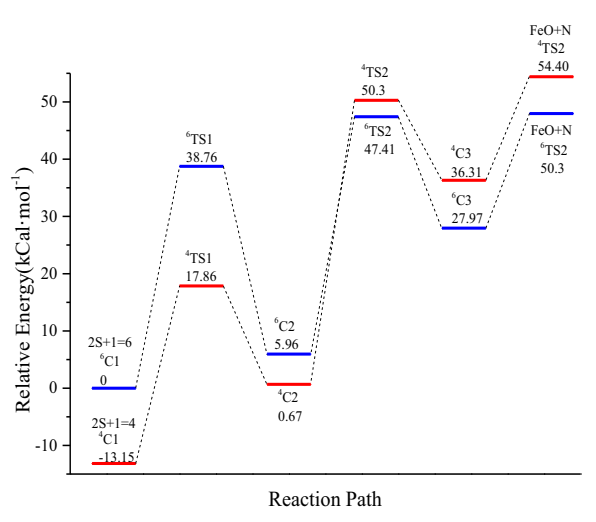

Figure 3. Diagram for the reaction of $\mathrm{Fe}+\mathrm{NO}$ on quartet/sextet state PES

With the $\mathrm{N}-\mathrm{Fe}-\mathrm{O}$ angles becoming larger, the constraint on $\mathrm{N}$ atom from $\mathrm{O}$ atom is weakened. The separation of the $\mathrm{N}$ atom from the complexes completed in fourth transition states, The energy barriers for the cleavage of $\mathrm{Fe}-\mathrm{N}$ bond are $18.09 \mathrm{kCal} / \mathrm{mol}$ and 20 $\mathrm{kCal} / \mathrm{mol}$ for quartet and sextet PESs.

Table 2. Energies of various species in reaction of $\mathrm{Fe}+\mathrm{NO} \rightarrow$ $\mathrm{FeO}+\mathrm{N}$ on two state PESs

\begin{tabular}{c|ccccc}
\hline \multirow{2}{*}{ Species } & \multicolumn{2}{|c}{$\mathrm{E}_{\mathrm{r}}(\mathrm{kCal} / \mathrm{mol})$} & & \multicolumn{2}{c}{$\mathrm{E}^{\prime}(\mathrm{kCal} / \mathrm{mol})$} \\
\cline { 2 - 3 } \cline { 6 - 7 } & $\begin{array}{c}\text { quartet } \\
\text { state }\end{array}$ & $\begin{array}{c}\text { sextet } \\
\text { state }\end{array}$ & & $\begin{array}{c}\text { quartet } \\
\text { state }\end{array}$ & $\begin{array}{c}\text { sextet } \\
\text { state }\end{array}$ \\
\cline { 1 - 3 } \cline { 6 - 7 } & -13.15 & 0 & & - & - \\
${ }^{4} \mathrm{C} 1\left({ }^{6} \mathrm{C} 1\right)$ & & & & \\
${ }^{4} \mathrm{TS} 1\left({ }^{6} \mathrm{TS} 1\right)$ & 17.86 & 38.76 & & 31.01 & 38.76 \\
${ }^{4} \mathrm{C} 2\left({ }^{6} \mathrm{C} 2\right)$ & 0.67 & 5.96 & & - & - \\
${ }^{4} \mathrm{TS} 2\left({ }^{6} \mathrm{TS} 2\right)$ & 50.30 & 47.41 & & 49.63 & 41.45 \\
${ }^{4} \mathrm{C} 3\left({ }^{6} \mathrm{C} 3\right)$ & 36.31 & 27.97 & & - & - \\
${ }^{4} \mathrm{TS} 3\left({ }^{6} \mathrm{TS} 3\right)$ & 54.40 & 47.97 & & 18.09 & 20 \\
\hline
\end{tabular}

\subsubsection{Crossing point between two PESs}


As shown in Fig. 3, there is a crossing point (CP) between the quartet and sextet state PESs. The crossing behavior in the thermal reaction of transition metal compounds was observed by Armentrout [28]. Shaik et al. $[29,30]$ confirmed such type of behavior and proposed that the phenomenon of two states of different multiplicities can dramatically affect the reaction mechanisms, rate constants, branching ratios, and temperature behaviors of organometallic transformations, which is termed as two-state reactivity (TSR). TSR, i.e., can make sure a thermal reaction which involves spin crossover along the reaction coordinate from reactants to products may find low energy paths for otherwise difficult processes.

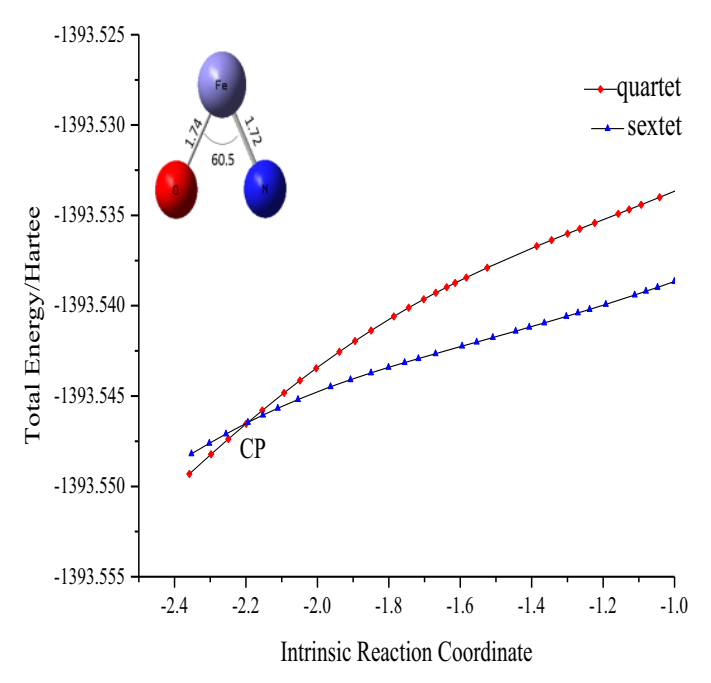

Figure 4. Potential energy cure-crossing point diagram between two spin state PESs

The crossing point (CP) and spin-crossover of TSR are important to understand the mechanism of $\mathrm{NO}$ activation on iron atom. Our calculations show that a crossing point exists between quartet and sextet PESs. Ulteriorly, the crossing point was verified by the intrinsic reaction coordinate (IRC) calculations. In the light of IRC calculation, the geometry of crossing point was received and listed in Fig. 4. According to the TSR, the reaction system may transform its spin multiplicity from the quartet to sextet state in the crossing region, which can lower the activation energy effectively, from 49.63 $\mathrm{kCal} / \mathrm{mol}$ to $46.74 \mathrm{kCal} / \mathrm{mol}$. Therefore, the minimum energy pathways can be described as: Fe+NO $(\mathrm{M}=4) \rightarrow$ $4 \mathrm{C} 1 \rightarrow 4 \mathrm{TS} 1 \rightarrow 4 \mathrm{C} 2 \rightarrow 6 \mathrm{TS} 2 \rightarrow 6 \mathrm{C} 3 \rightarrow 6 \mathrm{TS} 3$.

\section{Conclusion}

The B3LYP method combined with $6-311+\mathrm{G}(\mathrm{d}$, p) basis set was applied to investigate the reaction of $\mathrm{NO}$ activation on iron atom. For the activation of $\mathrm{NO}$ on $\mathrm{Fe}$ atom, our calculations suggest that the reaction should proceed via the quartet PES, in the vicinity of $\mathrm{CP}$, the reaction system will transform its spin multiplicity from the quartet to sextet state. Attribute to the $\mathrm{CP}$, the activation energy can be lowered effectively, from 49.63 $\mathrm{kCal} / \mathrm{mol}$ to $46.74 \mathrm{kCal} / \mathrm{mol}$, which derives from cleavage of N-O bond. And mechanism of the reactions on quartet and sextet PESs are similar. For the activation of $\mathrm{NO}$ on Fe dimer, simultaneously, reaction also proceed via low spin state (octet), the reaction system may transform its spin multiplicity from the octet to dectet state in the crossing region. Also, the $\mathrm{CP}$ can effectively lower activation energy from $49.53 \mathrm{kCal} / \mathrm{mol}$ to 45.33 $\mathrm{kCal} / \mathrm{mol}$, deriving from breaking of $\mathrm{Fe}-\mathrm{O}$ bond, mechanism of the reactions on octet and dectet PESs are similar. Results showed that the reaction of iron atom with NO was a typical two-state reaction (TSR). In the reaction channel, the crossing point appears, which would effectively reduce the activation energy and increase the release of reaction heat, play a significant and beneficial role in the kinetic and thermodynamic aspects of this catalytic reaction.

\section{Acknowledgments}

This work was supported by National Natural Science Foundation of China (No. 51278095), which are gratefully acknowledged.

\section{References}

1. Pastor G, Dorantes-Dávila J, Bennemann K.Physica B+ C.149 (1988).

2. Jellinek J, Garzon I L.Z. Phys. D: At., Mol. Clusters.20 (1991).

3. Hill C L, Prossermccartha C M.Coordin. Chem. Rev. 143 (1995).

4. Alonso J A.Chem. Rev. 100 (2000).

5. Dyson P J.Coordin. Chem. Rev. 248 ( 2004).

6. SU Yaxin, SU Along, CHENG Hao.J China Coal Soc.38(s1) (2013)

7. Gradon b, Lasek J. Fuel.89(11) (2010)

8. SU Ya-xin, SU A-long, CHENG Hao. J. China Coal Soc. 38(s1) (2013)

9. Blagojevic V, Orlova G, Bohme D K.J. Am. Chem. Soc. 127 (2005).

10. Heyden A, Hansen N, Bell A T, et al.J. Phys. Chem. B, 110 (2006).

11. Bansmann J, Baker S H, Binns C, et al.Surf. Sci. Rep. 56 (2005).

12. Sun Q, Li Z, Du A, et al.Fuel.96 (2012).

13. Gutsev G, Mochena M, Johnson E, et al.J. Chem. Phys. 125 (2006).

14. Frisch, M.; Trucks, G.; Schlegel, H. B.; et al. Gaussian 09, Revision A.02; Wallingford CT: Gaussian, Inc. (2009).

15. Becke A D.Phys. Rev. A.38 (1988).

16. Becke A, Roussel M.Phys. Rev. A.39 (1989).

17. Lee C, Yang W, Parr R G.Phys. Rev. B.37 (1988).

18. Ai H, Bu Y, Li P, et al.J. Chem. Phys. 123 (2005).

19. Ai H, Bu Y, Li P, et al.New J. Chem. 29 (2005).

20. Yang X-Y, Wang Y-C, Geng Z-Y, et al.Chem. Phys. Lett. 430 ( 2006).

21. Kwon K D, Kubicki J D.Langmuir. 20 (2004). 
22. Persson P, Nilsson N, Sjöberg S.J. Colloid Interface Sci. 177 (1996).

23. Arai Y, Sparks D.J. Colloid Interface Sci. 241 (2001).

24. Mebel A M, Hwang D-Y.J. Phys. Chem. 105 (2001).

25. Tatewaki H, Tomonari M, Nakamura T.J. Chem. Phys. 88 ( 1988).
26. NIST atomic spectra database. $<$ http://physics.nist.gov/asd3 $>$.

27. Brown W A, King D A.J. Phys. Chem. B. 104 (2000).

28. Armentrout P.Science. 251 (1991).

29. Shaik S, Danovich D, Fiedler A, et al.Helv. Chim. Acta. 78 (1995).

30. Schröder D, Shaik S, Schwarz H.Accounts. Chem. Res.33(2000). 